\title{
REAÇÃO DE MARACUJAZEIRO AMARELO A MELOIDOGYNE INCOGNITA RAÇA 3
}

\author{
M.J. De Marchi Garcia ${ }^{1}$, I.H. Fischer ${ }^{1}$, C.J. Bueno ${ }^{2}$, A.M. de Almeida ${ }^{1}$, \\ A.C. Sampaio ${ }^{3}$, S.R.S. Wilcken ${ }^{4}$, R.M.A. Bertani ${ }^{1}$
}

${ }^{1}$ Polo Regional de Desenvolvimento Tecnológico dos Agronegócios do Centro Oeste, Av. Rodrigues Alves, 40-40, CEP 17030-000, Bauru, SP, Brasil. E-mail: mjdemarchi@apta.sp.gov.br

\section{RESUMO}

\begin{abstract}
Neste trabalho estudou-se a reação de maracujazeiro amarelo 'Maguari' e 'Afruvec' ao fitonematoide Meloidogyne incognita raça 3, em casa-de-vegetação. Adotou-se o delineamento inteiramente casualizado, com três tratamentos (Maguari, Afruvec e Tomateiro cv. Rutgers) e quatro repetições, sendo a parcela constituída por um vaso contendo uma planta. Após seis meses, avaliou-se o índice de galhas e de massa de ovos nas cultivares de maracujazeiro amarelo e no tomateiro cv. Rutgers. A classificação da resistência ao fitonematoide foi feita utilizando o critério do fator de reprodução (FR). A 'Maguari' apresentou zero de índice de galhas e de massa de ovos, enquanto que 'Afruvec' mostrou baixo índice de galhas e massa de ovos comparativamente com o tomateiro cv. Rutgers. De acordo com o FR, a 'Maguari' enquadrou-se como imune ao nematoide, sendo a 'Afruvec' resistente e o tomateiro cv. Rutgers como suscetível.
\end{abstract}

PALAVRAS-CHAVE: Passiflora sp., nematoide de galhas, resistência, fator de reprodução.

\section{ABSTRACT}

REACTION OF YELLOW PASSION FRUIT TO MELOIDOGYNE INCOGNITA RACE 3. This study concerned the reaction of yellow passion fruit 'Maguary' and 'Afruvec' to the phytonematode Meloidogyne incognita race 3 in greenhouse conditions. An entirely randomized experimental design with 3 treatments ('Maguary', 'Afruvec', and tomato cv. 'Rutgers') and 4 repetitions was used, each plot consisting of 1 vase containing 1 plant. After 6 months, an evaluation was made of the index of galls and egg mass in the yellow passion fruit varieties and in the tomato cv. 'Rutgers'. The classification of resistance to the phytonematode was made by criterion of the reproduction factor (RF). 'Maguary' presented a zero index of galls and egg mass, while 'Afruvec' showed a low index of galls and egg mass in relation to the tomato cv. Rutgers. According to the RF, 'Maguary' was characterized as immune to the phytonematode, while 'Afruvec' was resistant, and the tomato cv. 'Rutgers' was susceptible.

KEY WORDS: Passiflora sp., root-knot nematodes, resistance, reproduction factor.

OBrasil é o maior produtor mundial de maracujá amarelo, com produção aproximada de 491.619 toneladas (FNP, 2007).

A expansão da área plantada com maracujazeiro fez-se acompanhada do surgimento e agravamento de grande número de doenças, por decorrência da falta de aprimoramento do sistema de produção. Estes problemas fitossanitários têm reduzido o tempo de exploração econômica da cultura e inviabilizado o seu cultivo em determinadas regiões (FISCHER, 2003; Portal do Agronegócio, 2006).
Dentre os problemas fitossanitários que afligem a fruticultura nos países de clima tropical e subtropical estão os nematoides parasitos de plantas (LORDELLO; LORDELLO, 1992), dentre os quais o gênero Meloidogyneé consideradoomaisimportante(SASSER;FRECKMAN,1987).

Para que a expansão da cultura do maracujazeiro seja feita adequadamenteénecessário o conhecimento da reação das cultivares utilizadas aos diferentes agentes fitossanitários, incluindo-seaíos nematoides.

Há relatos de resistência de maracujazeiro amarelo a nematoides de galhas (KLEIN et al., 1984; Sharmaet

${ }^{2}$ Instituto Biológico, Centro Experimental Central, Campinas, SP, Brasil.

${ }^{3}$ Universidade Estadual Paulista, Faculdade de Ciências, Departamento de Ciências Biológicas, Bauru, SP, Brasil.

${ }^{4}$ Universidade Estadual Paulista, Faculdade de Ciências Agronômicas, Departamento Produção Vegetal/Defesa Fitossanitária, Botucatu, SP, Brasil. 
al., 2001; SHARMA et al., 2002), inclusive das variedades 'Maguari' e 'Afruvec'a Meloidogyne incognita raça 2, M. hapla e M. javanica (GARCIA et al., 2008).

Diante da importância do cultivo do maracujáamarelo no Brasil e dos problemas causados por Meloidogyne spp. na fruticultura tropical, realizou-se o presente estudo com o objetivo de verificar a reação das variedades 'Maguari' e 'Afruvec', de maracujazeiro amarelo, ao fitonematoide $M$. incognita raça 3 .

$\mathrm{O}$ experimento foi instalado em condições de casa-de-vegetaçãona Agência Paulista de Tecnologia dos Agronegócios (APTA), Polo de Desenvolvimento Tecnológico do Centro Oeste, Unidade de Pesquisa e Desenvolvimento de Bauru, SP.

A população pura de $M$. incognita raça 3 foi isolada a partir de raízes de algodoeiro proveniente do Município de Barreiras, BA, e multiplicada em raízes de quiabeiro cv. Santa Cruz mantidos em vasos com substrato previamente autoclavado.

Foram utilizadas as variedades 'Maguari' e 'Afruvec' de maracujazeiro amarelo. Realizou-se a semeadura direta em vasos de $2 \mathrm{~L}$, contendo uma mistura previamente autoclavada de solo, areia e esterco bovino, na proporção de 2:1:1.

Oinóculo, composto por ovos e eventuais juvenis infectantes de M. incognita raça 3, foi obtido pela extração das raízes de quiabeiro, seguindo o método proposto por CoOlen; D'Herde (1972).

Colocou-se 2,5 mL de suspensão contendo 5.000 ovos e eventuais juvenis de segundo estádio (J2) do nematoide em dois orifícios abertos no solo dos vasos ao redor das mudas com 30 dias após a emergência.

O delineamento experimental foi inteiramente casualizado, com três tratamentos (maracujazeiros 'Maguari' e 'Afruvec' e Tomateiro cv. Rutgers) e quatro repetições por tratamento, sendo cada parcela constituída de uma planta por vaso. Tomateiro 'Rutgers' foi utilizado como padrão de viabilidade do inóculo.

Os parâmetros avaliados, após seis meses da inoculação (16/2/2007 a 2/8/2007) foram: número de galhas e massa de ovos nas raízes, utilizando-se a escala de notas proposta por TAYLOR; SASSER (1978), e a população final do fitonematoide determinada pelo número de ovos e juvenis de segundo estádio nosistema radicular, extraídos pelo método proposto por COOLEN; D'HERDE (1972). As cultivares de maracujazeiro amarelo e o tomateiro foram classificados quanto à resistência ao nematoide pelo critério de OOSTENBRINK (1966), ou seja, por meio do fator de reprodução (FR), sendo FR = 0: imune (I); $0<$ FR < $=1$ : resistente $(\mathrm{R})$ e FR $>1$ : suscetível $(\mathrm{S})$.

De acordo com os dados dos índices de galhas e massa de ovos (Tabela 1), constatou-se que a cultivar 'Maguari' não apresentou galhas e nem massa de ovos. A 'Afruvec' apresentou baixo índice de galhas e de massa de ovos comparativamente com o tomateiro 'Rutgers', que apresentou índice máximo tanto de galhas quanto de massa de ovos.

Quanto ao fator de reprodução do nematoide (Tabela 1), conclui-se que a cv. 'Maguari' comportou-se como imune ao nematoide, enquanto que a 'Afruvec' resistente e o tomateiro cv. 'Rutgers' como suscetível. Acredita-se que o baixo fator de reprodução do nematoide nas raízes do tomateiro deve-se ao período de seis meses do ensaio, fazendo com que o nematoide desintegrasse grande parte do sistema radicular.

RITZINGER et al. (2003a) e RITZINGER et al. (2003b) constataramquealgumasespécies de Passiflora podemapresentar galhas resultantes de infecção de Meloidogyne, mas a progressão da infecção pode não ocorrer. Esses autores verificaram que, apesar de P. edulis f. flavicarpa e $P$. coerulea apresentarem galhas, não propiciavam a reprodução do nematoide, sendo consideradas não hospedeiras;jáP.alatae P.quadrangularisapresentavam galhas e massa de ovos, sendo consideradas, portanto, boas hospedeiras. El Moor et al. (2009) verificaram baixas taxas de penetração e estabelecimento de $M$. incognita e $M$. javanica em diferentes cultivares de maracujazeiro amarelo.

Informações científicas sobre a resistência de variedades de maracujazeiro amarelo frente à ação de $M$. incognita raça 3 são escassas. Há trabalhos de reação de materiais de Passiflora spp., incluindo a espécie $P$. edulis f. flavicarpa, a M. javanica (SHARMA et al., 2002), M. incognita e M. incognita raça 1 (Costa et al., 2001; Silva Junior et al., 1988; Klein et al., 1984). GARCIA et al. (2008) constataram que as cultivares 'Maguari' e 'Afruvec', de maracujazeiro amarelo, são resistentes a $M$. incognita raça 2 , enquanto que no presente trabalho a'Maguari' apresentou-se imunee a 'Afruvec' resistente a M. incognita raça 3. Os dados do presente trabalho vão de encontro com os relatos de RitZINGER et al. (2003a) e RitZINGer et al. (2003b) quanto ao fato de espécies de $P$. edulis f. flavicarpa não serem boas hospedeiras para o fitonematoide do gênero Meloidogyne.

Tabela 1 - Índice de galhas (IG), massas de ovos (IMO) e o fator de reprodução(FR) de Meloidogyne incognita raça 3 nas cultivares 'Maguari' e'Afruvec' de maracujazeiro amarelo e no tomateiro $\mathrm{cv}^{\prime}$ Rutgers', seis meses após a inoculação.

\begin{tabular}{lccc}
\hline Tratamentos & $\mathrm{IG}^{1}$ & $\mathrm{IMO}^{1}$ & $\mathrm{FR}^{2}$ \\
\hline 'Maguari' & 0 & 0 & $0 \mathrm{I}$ \\
'Afruvec' & 2 & 2 & $0,1 \mathrm{R}$ \\
Tomateiro cv. 'Rutgers' & 5 & 5 & $3,7 \mathrm{~S}$
\end{tabular}

${ }^{1}$ Escala de notas de TAYLOR; SASSER (1978): $0=0$ galhas ou massa de ovos; 1 = 1 a 2 galhas ou massa de ovos; 2 = 3 a 10 galhas ou massa de ovos; $3=11$ a 30 galhas ou massa de ovos; $4=31$ a 100 galhas ou massa de ovos e $5=$ mais de 100 galhas ou massa de ovos.

${ }^{2} \mathrm{FR}$ (Fator de reprodução), sendo FR = 0: imune (I); $0<$ FR $<=1$ : resistente $(\mathrm{R})$ e FR $>1$ : suscetível (S). 


\section{REFERÊNCIAS}

COOLEN, W.A.; D'HERDE, C.J. A method for quantitative extraction of nematodes from plant tissue. Merebelke: State Nematology Research Station, 1972. 77p.

COSTA, D. da C; LIMA, A.A.; JESUS, R.L. A.Efeito de dois níveis de inóculo na reação de espécies de maracujazeiro a Meloidogyne incognita. Revista Brasileira de Fruticultura, v.23, n.1, p.1 86-189, 2001.

EL MOOR, R.D.; PEIXOTO, J.R.; RAMOS, M.L.G.; MATTOS, J.K.A. Reação de genótipos de maracujazeiro azedo aos nematóides de galhas (Meloiodgyne incognita e Meloidogyne javanica). Bioscience Journal, v.25, n.1, p.5359, 2009.

FNP Consultoria \& Agroinformativos. Agrianual 2007: anuário estatístico da agricultura brasileira. São Paulo, 2007, p.387-394. Maracujá.

FISCHER, I.H. Seleção de plantas resistentes e de fungicidas para o controle da "morte prematura" do maracujazeiro, causada por Nectria hematococca e Phytophthora parasitica. 2003. Dissertação (Mestrado em Fitopatologia) - Escola Superior de Agricultura "Luiz de Queiroz", Universidade de São Paulo, Piracicaba, 2003.

GARCIA, M.J.D.M.; ALMEIDA, A.M.; WILCKEN, S.R.S.; FISCHER, I.H.; SAMPAIO, A.L.; JESUS, A.M.; FUMIS, T. Reação de maracujazeiro amarelo 'Afruvec' e 'Maguary' a Meloidogyne spp. Arquivos do Instituto Biológico, São Paulo, v.75, n.2, p.235-238, 2008.

KLEIN, A.L.; FERRAZ, L.C.C.B.; OLIVEIRA, J.C. Comportamento de diferentes maracujazeiros em relação ao nematóide formador de galha. Pesquisa Agropecuária Brasileira, v. 2, n.19, p.207-209, 1984.

LORDELLO, A.I.L.; LORDELLO, R.R.A. Nematóides em frutíferas: cuidado com as mudas. O Agronômico, v.44, p.1-3, 1992.

OOSTENBRINK, M. Major characteristics of the relation between nematodes and plants. Mededelingen Van De Landbouwhogeschool, v.66, n.4, p.1-46, 1966.
PORTAL DO AGRONEGÓCIO. Definhamento precoce do maracujazeiro na Bahia e a pinta verde do maracujá. 2006. Disponível em: < http://www.portaldoagronegocio.com.br/ index.php? $\mathrm{p}=$ texto $\& \& \mathrm{idT}=753>$. Acesso em: 20 nov. 2006.

RITZINGER, C.H.S.P.; SHARMA, R.D.; JUNQUEIRA, N.T.V. Nematóides. In: SANTOS FILHO, H.P.; JUNQUEIRA, N.T.V. (Ed.). Maracujá: fitossanidade. Brasília: Embrapa Informação Tecnológica, 2003a. p.22-24, (Frutas do Brasil, 32).

RITZINGER, C.H.S.P.; SHARMA, R.D.; JUNQUEIRA, N.T.V. Manejo da bactéria e de nematóides em maracujazeiro In: SIMPÓSIO BRASILEIRO SOBRE A CULTURA DO MARACUJAZEIRO, 6., 2003, Campo dos Goytacazes, RJ. Anais. Campo dos Goytacazes: 2003b. p.24-27.

SASSER, J.N.; FRECKMAN, D.W. A world perspective on nematology: the role of the society. In: VEECH, J.; DICKSON, D.W. (Ed.). Vistas on nematology: a commemoration of the twenty-fifth anniversary of the Society of Nematologists. Hyatsville: The Society of Nematologists, 1987. p.7-14.

SHARMA, R.D.; JUNQUEIRA, N.T.V.; GOMES, A.C. Pathogenicity and reproduction of Meloidogyne javanica on yellow passion fruit hybrid. Nematologia Brasileira, v.25, n.2, p.247-249, 2001.

SHARMA, R.D.; JUNQUEIRA, N.T.V.; GOMES, A.C. Reaction of passion fruit varieties to the root-knot nematode, Meloidogyne javanica. Nematologia Brasileira, v.26, n.1, p.93-96, 2002.

SILVA JÚNIOR, P.F.; TIHOHOD, D.; OLIVEIRA, J.C. Avaliação da resistência de maracujazeiros (Passiflora spp.) a uma população de Meloidogyne incognita raça 1. Nematologia Brasileira, v.12, p.103-109, 1988.

TAYLOR, A.L.; SASSER, J.N. Biology, identification and control of rootknot nematodes (Meloidogyne spp.). Raleight: North Caroline State University, 1978. 111p.

Recebido em 6/4/09

Aceito em 30/12/09 